\title{
The Existential Turn: Reappraising Being and Time's Overcoming of Metaphysics
}

Rufus Duits

$B$ eing and Time had a transcendental agenda. Why then does one not find a recognisable theory of categories in its pages? It claims existential or practical import. Why does one find no theory of the will?

The task of this paper is to propose an answer to these related questions. It amounts to an attempt to work through conceptually step by step Heidegger's so called "overcoming of metaphysics". It is true of course that the locution, "the overcoming of metaphysics", does not appear in Being and Time. The discourse of the overcoming of metaphysics is held by Heidegger's commentators to belong to a period post-dating the early work, after the socalled Kehre. I shall stubbornly evade this knotty issue of Heidegger interpretation here. For my purposes it suffices merely if our understanding of Being and Time, its content, intent and consequence, can be deepened or expanded if it is read in the light of the task of overcoming metaphysics — or at least in the light of that task as it is to be conceived in the context I shall present here. What is to be understood by the phrase "the overcoming of metaphysics"?

Risking extreme over-simplification for the subtractive purposes of this essay, Heidegger's determination of metaphysics will here be construed as a particular configuration of concepts which grounds all historical manifestations of the West. This configuration is organised by binary conceptual oppositions structured along two primary axes which may be topographically conceived as orthogonal. These axes concern two fundamental distinctions, which, we will suppose, form the basis of all other oppositions and hierarchies that conform metaphysical conceptuality. One of these fundamental distinctions is that of theory and praxis, the other is that of subject and object. Reduction to such a simple schema has the advantage of clarifying the nature of Heidegger's achievement.

The word "overcoming", on the other hand, denotes, not, in general, for Heidegger, abandonment for the sake of something wholly new, but rather a return to an origin in terms of which the essence of that which is overcome is first adequately understood. From a text belonging to a later period: "The overcoming must conceive itself in the first place as such, and take its step in

(C) 2010 Rufus Duits http://www.kritike.org/journal/issue 7/duits june2010.pdf ISSN 1908-7330 
what is essential, attempting thereby at the same time first to constitute that which is overcome as such." 1 Add: "Overcoming is the getting over of that which is overcome into its having-been-ness-a returning to the beginning of the beginning." "2 Nevertheless, for our purposes here, neither beginnings nor origins will be important.

Further, the entire procedure by which, I allege, Being and Time overcomes metaphysics is not here to be outlined. What then am I to be concerned with? My concern is only with the first conceptual procedures by which the metaphysical oppositions are broken down, revealing a new philosophical landscape situated beyond the horizon of their conceptuality. My modest aim is to outline the basic logic of these procedures-or at the very least some thereof-in the precise terms of, firstly, Being and Time's rendering obsolete of the Kantian theory of categories, and, secondly, Being and Time's rendering obsolete of the Kantian conception of the will.

Two final admonitions and an apology: The usual caveat of Heidegger interpretation, whereby all pretension to completeness is foresworn at the outset, is here made explicit. My task is in the very first place not a survey of Heidegger's relation to Kant. A further caution concerns my use of texts. My analysis is systematic, not expository; and I am aiming for a certain independence from my historical sources. What, however, could be the contemporary significance of my task? Has not Heidegger's overcoming of metaphysics already been thoroughly worn out to the point of anachrony? Perhaps. My point in reopening the debate in this limited context is twofold: On the one hand, I feel that the later Heidegger's conception of the "beinghistorical" role of Being and Time, attested to again and again in, for example, the Contributions to Philosophy, has received less than sufficient notice within a tradition of scholarship so keen to emphasise the Kehre. On the other hand, I also feel that the proper significance of the reorganisation of philosophical concepts accomplished in Being and Time, the gathering or reference point of so much subsequent thought, is today too frequently forgotten. Hence my title.

\section{I}

In the first place it must be made thematic how the Kantian doctrine of categories itself is here to be understood. A standard dictionary of philosophical terminology will probably define a category simply as an ultimate class or genera. A doctrine or table of categories would then be an exhaustive or complete list of these. If this most general meaning were employed, one would indeed find categorical constellations in Being and Time- the three modes of being, existence, Zubandenheit and Vorbandenheit, the obvious example. But

1 Martin Heidegger, Metaphysik und Nibilismus (Frankfurt: Gesamtausgabe Bd. 67, Vittorio Klostermann, 1999), 11. Die Überwindung muß sich zuvor begreifen und ihren Schritt im Wesentlichen tun und in einem damit zugleich und erst das zu Überwindende als ein solches auszumachen versuchen. (All translations of Heidegger's text are my own.)

${ }^{2}$ Ibid., 14. "Überwindung ist...Verwinden des Überwundenen in seine GewesenheitZurückgeben in das Anfangen des Anfanges." 


\section{THE EXISTENTIAL TURN}

the traditional metaphysical meaning of category is not so general. Rather, since metaphysics, at least since Descartes, exhibits a fundamental epistemological orientation, then in the first instance a category can accordingly be understood as a fundamental or essential class or genera that determines knowledge, a doctrine of categories an exhaustive list of these classes or genera. It is in this epistemological sense that Kant offers his table of categories.

There is no necessity for lengthy Kant exegesis here, nor for solutions to the many difficult interpretative issues that surround his deductions and formulations of the categories. For my purposes it suffices to demonstrate the grounding of Kant's theory within the constellation of metaphysical oppositions. This will inevitably be a process of simplification-but hopefully also of clarification and precision.

Most significantly, Kant's categories are functions of unity. Unification is the most basic principle of judgement, which is the essential task of the faculty of understanding. In general, this function of unity consists in the bringing of a manifold under a single representation through its subsumption under a rule or law. Since the categories first make possible synthetic a priori judgements, upon which the various forms of discursive judgements are based, they are defined to be transcendental: they constitute, in part, the mode of all possible cognition of the transcendental subject.

Each category corresponds to what Kant calls a schema. "We thus find that the schema of each category contains and makes capable of representation only a determination of time .. . The schemata are thus nothing but a priori determinations of time in accordance with rules." 3 This nexus of categories, schemata and time begs further specification.

The connection drawn between the categories, on the one hand, and time, the pure form of inner intuition, on the other, through the mediation of schemata, is made clearer by the transcendental deduction of the first edition of the Critique of Pure Reason. According to a popular account of the argument of this section-which shall here be uncritically adopted for the purposes of exposition -, Kant's initial and foundational premise is as follows: "Whatever the origin of our representations, whether they are due to the influence of outer things, or are produced through inner causes, whether they arise a priori, or being appearances have an empirical origin, they must all, as modifications of the mind, belong to inner sense. All our knowledge is thus finally subject to time, the formal condition of inner sense." 4 From this premise it will be inferred: the categories are a priori valid for empirical objects, or first make possible the experience of these objects, insofar as they-the categories-are determinations of the form of intuition, i.e. time, in which these objects necessarily appear.

\footnotetext{
${ }^{3}$ Immanuel Kant, Critique of Pure Reason, trans. by Norman Kemp Smith (London: Macmillan, 1933), A145, B184.

${ }^{4}$ Ibid., A98-99.
} 
Now, being functions of unity, these categorical operations are synthetic. Kant explicitly distinguishes three separate synthetic operations that first make experience as such, and thus experience of objects, possible:

1. The synthesis of apprehension in intuition. This is the only operation explicitly conceived as immediately concerning time itself. This synthesis ensures, on the one hand, that a manifold of successive appearances are experienced as belonging to one and the same time, and, on the other, therefore, that time is itself first experienced-and experienced as successive, or having the structure of succession. Time as such, as a unity, is here first distinguished from the successive manifold within it.

2. The synthesis of reproduction (or, in reference to Hume, "association") in imagination. According to Kant, experience is only possible insofar as it is determined by regularity. This regularity is grounded in a transcendental synthesis which allows the reproduction of appearances. To illustrate Kant's thought here by means of his own example: if I try to draw a line in thought, I can do so only insofar as my present representation is always accompanied by my preceding representations; for otherwise my line, as it were, would never get going, no distance would ever be created. The same, of course, is true in general of my representation of time. I can only have a representation of succession, of the passing away of time, insofar as a memory of past moments accompanies the representation of the present moment in terms of their relationships of succession.

3. The synthesis of recognition in a concept. Kant's third synthesis (in the first place) adds the point that the reproduced representations that determine the present representation must be recognised as previously present representations, or as the same as previously present representations: "If we were not conscious that what we think is the same as what we thought a moment before, all reproduction in the series of representations would be useless." 5

It is clear that time functions in each of these syntheses as the principle according to or upon which unification is carried out. As the a priori functions of unity that first make experience-and the objects of experiencepossible, the categories must, then, be particular determinations of time.

(And insofar as the categories are laws of objects in general, whether intelligible or intuitive, and must therefore be laws of understanding as well as determinations of inner sense, both intuition and understanding must share in the same functions of unity, the same syntheses, and their objects (objects of intuition and objects of thought) must then be subject to the same a priori conditions.-And with this demonstration of the necessary determination of the objects of intuition by the laws of thought, the categories, the transcendental deduction has fulfilled its task.)

The categories function as principles of the necessary unity of experience insofar as they are determinations of time, of the form of inner sense. Conceived in this way, that is, in their temporal determination, they

${ }^{5}$ Ibid., A103. 


\section{THE EXISTENTIAL TURN}

receive the name schemata: "The schemata are thus nothing but a priori determinations of time in accordance with rules." It is not ingenuous of Kant to suggest that schemata are "some third thing" existing halfway between the judicial function of understanding and the appearances of intuition, homogenous with both. Rather, the schemata just are the categories, the "pure concepts of understanding", considered in terms of their application to appearance.

At this point, I pause to mention Heidegger's insistence on the importance of productive imagination to Kantian epistemology. Kant writes: "The schema is in itself always a product of imagination." A manageable way of grasping the role performed by the imagination here could involve understanding the schemata to concern productions beyond the horizon of presence; in other words, as determinations of time, the schemata are only possible on the condition of a faculty of producing "images" outside of the immediate present. This task requires a distinct faculty, according to Kant: the transcendental imagination. Heidegger is right to insist on its importance to critical philosophy if indeed, as he is not the only one to claim, the chapter on the transcendental schematism is the crux of the argument of the first Critique.

The three syntheses outlined above are temporal in that they are functions of unification of the manifold within the form or structure of time. They themselves, however, are unified, or find their mutual possibility, within a fourth synthesis which is the highest principle of transcendental idealism in general: the transcendental unity of apperception. This is the most basic determination of the Kantian subject. The principle of unity of the unifying syntheses of the manifold through the determination of time, the transcendental unity of apperception, must be the unity of temporal determination in general. It is to be finally understood as the "original unchangeable" consciousness of self-identity, which first makes possible the appearance of the manifold within one continuous experience.

The doctrine of the transcendental unity of apperception thematically corresponds to, and is introduced immediately before, the doctrine of the transcendental object. This latter concept, I contend, does not belong, as Kemp Smith $^{7}$ and others have maintained, to a prior, pre-critical standpoint, but rather forms the very necessary transcendental correlative to the synthetic unity of apperception. Just as consciousness of self-identity must accompany all our representations insofar as they are unified within one experience, so the concept of the transcendental object, the concept of an object in general, confers on representations their objectivity. "The pure concept of this transcendental object, which in reality throughout all our knowledge is always one and the same, is what can alone confer upon all our empirical concepts in general relation to an object, that is, objective reality." 8 It must be emphasised that the doctrine of the transcendental unity of apperception makes no sense in the

${ }^{6}$ Ibid., A140, B179.

7 Norman Kemp Smith, A Commentary to Kant's "Critique of Pure Reason," 2nd ed. (London: Macmillan, 1923).

${ }^{8}$ Kant, Critique of Pure Reason, A109. 
absence of an opposing transcendental pole which determines the constitution of objects for a subject. The subject would have no objects of experience and thus there would be no basis for the representation of its self-identity. On the other hand, without the transcendental unity of apperception there would be no principles of synthesis that would allow the concept of an object of experience, a unity within the manifold, to become available. Subject and object make each other possible, are mutually necessary for one another, and for the possibility of knowledge in general, the precise determination of which is the final aim of critical philosophy.

Subject and object form one polarity definitional of metaphysical conceptuality. In the Kantian philosophy, considered by many to be the highwater mark of the tradition of Western metaphysics, the subject and object are impossible without temporal synthesis; that is, they are both made possible by the presupposition of time. Time forms the principle of unity on the basis of which an object can first stand opposite a self-identical, that is, a knowing subject. On the other hand, of course, they themselves make the representation of time first possible.

If it could be shown that the understanding of time which determines this basic opposition is phenomenologically erroneous, that would effectively put into question the entire metaphysical conceptuality which rests upon it. It is just this move which Heidegger attempts in Being and Time.

Rather than turning immediately to Heidegger's analysis of temporality in Being and Time, it will be instructive first to examine the critique he issues against Kant in the Kantbook. It is possible to understand Heidegger's argument here as deconstructive. Whilst Kant advocates the necessity of synthesis for the possibility of experience, and emphasises the role played by time in forming the medium, as it were, for such synthesis, he yet fails to appreciate that time itself, if it is to perform as a unifying function, must form an original unity. The concept of time which, according to Heidegger, is always in play in the Kantian analyses, and never once put into question or explicitly developed, is that of Aristotle, and the conception which remains unchallenged throughout the entire history of metaphysics. Time is implicitly conceived as a succession of now-moments. In the last analysis, of course, it is this conception of time that grounds metaphysics in Heidegger's sense, that which determines the entire system of oppositions upon which metaphysical conceptuality rests.

A succession of now-moments is not a unitary whole. It is pure dispersion, the dissipation of moments throughout the three dimensions of past, present and future. But time conceived in this sense cannot function in the way Kant requires in order to secure the unity of the syntheses that first make experience and thus knowledge possible.

To take the first of the three syntheses outlined above, the synthesis of apprehension in intuition, Kant writes: "each representation, insofar as it is contained in a single moment, can never be anything but absolute unity. In order that unity of intuition may arise out of this manifold . . . it must first be run 
through, and held together." It is here implicitly recognised that if time is finally conceived in terms of a pure succession of moments, precisely then the synthesis necessary to make human knowledge possible is impossible. Every moment would be closed up in itself with no intrinsic or immanent relation to any other moment and no principle for the unity of a plurality of moments. Experience would then be absolutely monadic, which, of course, contradicts the very concept of experience (German erfahren, meaning originally durchreisen, to travel through, obviously implicating time). And then time itself would not be experienced. But then Kant writes, for example: "We represent the timesequence by a line progressing to infinity, in which the manifold constitutes a series of one dimension only; and we reason from the properties of this line to all the properties of time, with this one exception, that while the parts of the line are simultaneous the parts of time are always successive." 10

It is therefore a case of opposing Kant to himself. Whilst time is implicitly conceived as a pure succession, on the other hand, it is also implicitly recognised that time conceived in this way cannot perform the function required by the transcendental deduction. Accordingly, Heidegger re-interprets Kant's three syntheses in terms of the concept of ecstatic temporality that provided the conclusions of Being and Time. Time conceived as ecstatic temporality is itself temporal. It is time all the way down, as it were. The temporal determination does not finish with a static structure of succession, rather the temporal structure is itself dynamic, ecstatic, is itself temporal.

The three syntheses of the transcendental deduction become the three dimensions of ecstatic temporality: Gegenwart, Gewesenheit and Zukunft. The synthesis of apprehension in intuition enables time itself to be first experienced insofar as it allows the now as such to come to experience. The possibility of the present in general requires this synthesis. On the other hand, the synthesis of reproduction allows for the accompaniment of the present, the present representation, by preceding representations and thus, equally necessary for the experience of time, makes possible the past, Gewesenheit. Finally, the synthesis of recognition in the concept is tied by Heidegger to the ecstasy of the future. Heidegger's argument in this regard is a little more complicated and certainly more contrived, for it is initially unclear what this synthesis could have to do with futuricity. This synthesis concerns the identification or identity of the objects of representation. In order that experience can take on temporal form, the form of continuum, and not break up into a series of unrelated units, it must be the case that the present object of representation be identified with a previous identification. Heidegger points out that only on the basis of this synthesis do the previously elaborated syntheses first become possible. Kant had written: "If we were not conscious that what we think is the same as what we thought a moment before, all reproduction in the series of representations would be useless." The synthesis of recognition is the transcendental possibility of identity in general, and only given this possibility of identity do the other

\footnotetext{
${ }^{9}$ Ibid., A99.

${ }^{10}$ Ibid., A33, B50.
} 


\section{R. DUITS 101}

two syntheses become functional. The synthesis of recognition provides the horizon of identity in advance. "It explores in advance... what must be held before us in advance as the same in order that the apprehending and reproducing syntheses in general can find a closed, circumscribed field of beings within which they can attach to what they bring forth and encounter, so to speak, and take them in stride as beings." 11 In this sense, the synthesis of recognition determines the horizon in which beings are first available in general, and Heidegger designates this determination the future.

If the three syntheses of the transcendental deduction are in the last analysis to be conceived as ecstatic dimensions of temporality, and if, as Kant claims, they are the conditions of possibility of experience in general, then all experience is reducible to the functions of ecstatic temporality, all determination of experience as such is temporal. In Heidegger's own language: original temporality is the horizon of disclosure.

This re-working of the transcendental deduction in terms of the ecstatic function of temporality reveals the kernel of truth that Heidegger recognises in Kant's theory of the conditions of experience. But it makes problematic the subject-object dichotomy that conceptually underpins Kantian epistemology. For if it turns out that temporality-or indeed timeconstitutes the principle of synthesis in general, and thus most importantly, the synthesis of transcendental apperception, on the one hand, and that it is the horizon of objectivity on the other, then it would seem that rather than constituting the objects in opposition to its subjectivity, the subject itself simply is the temporal form of all experience, conceptual or intuitive. Time in this sense cannot merely be the pure form of inner intuition. For the inner would no longer be differential from the outer. The entire Kantian epistemological enterprise of determining the extent of metaphysical knowledge, which is grounded on the subject-object paradigm, is, however, thereby thrown into question.

To open finally, if briefly, and in the interests of a certain conceptual completeness, onto the phenomenological account of temporality given in Being and Time: it is, among other things, intended to dissolve this conceptual opposition. The fundamental conceptual innovations of this enterprise are "Dasein" and "world". Rather than reinstating the dualism of subject and object, these concepts outline a phenomenological unity of the world and its intelligibility. Dasein is not opposed to the world; Dasein is in the world, as the manifold interrelationships of meanings, references and significations which constitute the world. But this phenomenological unity is only possible on the conceptual basis of an ecstatic understanding of time.

11 Heidegger, Kant und das Problem der Metaphysike (Frankfurt: Vittorio Klostermann, 1998, translated as Kant and the Problem of Metaphysics by Richard Taft Indiana University Press, 1997]), 186. Sie erkundet im voraus...auf das, was im vorhinein als das Selbige vorgehalten sein muß, damit die apprehendierende und die reproduzierende Synthesis überhaupt einen geschlossenen Umkreis von Seiendem vorfinden können, innerhalb dessen sie das, was sie beibringen und antreffen, als Seiendes gleichsam anbringen und hinnehmen können. 


\section{THE EXISTENTIAL TURN}

Time is no longer conceived as an arithmetical form of phenomena. It is rather conceived as the mode of being of Dasein itself. It is not something in addition to or dependent on Dasein; it is the way in which Dasein is; that is, it conforms the meaning-structure of the world. The phenomenon of understanding, the intelligibility of the world, just is the temporal dynamic. The significance structures are mapped out by the projective character of temporality, by its directionality and the primacy of the ecstasy of the future. The objects that appear, or, to use Heidegger's vocabulary, are disclosed, are so only insofar as they are determined by the temporal matrix of meaningful relations. This means that objects do not stand opposed to a subject; they are rather nodes of the relational structures of intelligibility which constitute the subjectivity-if we are still inclined to use such words-of the subject. Subjectivity would become the relational structure of objectivity. The two would be therefore both ontologically and epistemologically inseparable from one another.

For this reason, the structure of Dasein's being could not be elaborated in terms of categories. That would attribute to Dasein the wrong mode of being-that of Vorhandenheit. It is not merely nomenclature to insist that Dasein alone ex-ists. The structural moments of this being thus bear the name existentials. Existentials have the function of outlining the possibility of Dasein's understanding. Only in this do they resemble the Kantian categories, which they replace. But they are not to be conceived as ultimately static functions, epistemologically legislating for experience from a constitutive distance, and they are even less properties adhering mysteriously to substances subjective and objective, their ontological possibility veiled. They are rather moments of original temporality, and for this reason they are to be understood as structural, as conforming structures. They are also no longer epistemological, but ontological. Most importantly, they are to be conceived as ecstatic, as ways in which Dasein temporally is, and temporally must be in virtue of the very structure of temporality. The shift from category to existential as regards the conditions of the configuration of world thus fundamentally rests upon a reconceptualisation of time.

Presence as such is constituted by the temporalising of temporality, the dynamic of which, as it were, splits static being, opening the space in which objects can first make an appearance, enopens the original relationality in which beings can first become intelligible, receive a signification, take on definition. The constituting of objects is not a position over and against subjectivity, as it is for Kant; it is rather the determination of beings within the intelligible structures of temporal understanding. The logic integral to the ecstatic conception of time, time as temporal all the way down, thus leaves no room for the epistemological opposition of subject and object. This basic axis of metaphysical conceptuality is collapsed. Time is not simply the outer form of objectivity, but constitutes objects in the meaning of their being; at the same time it is not simply a form belonging to the cognitive apparatus of the subject, but is rather the mode of being in which subjectivity consists. 


\section{R. DUITS 103}

Note once again though that Kant is not simply "wrong"; his concepts themselves put the rigor of the dichotomy into question.

\section{II}

It was suggested at the outset that the two basic conceptual oppositions configuring metaphysical thought are that of subject and object and that of theory and praxis. There is, of course, another basic opposition that has pervaded modern philosophical thought, and indeed perhaps continues to do so much more obviously than either of these two. This is the opposition known in terms of mind and body. Why do I not designate this metaphysically fundamental? Because, it seems to me, it depends upon—or at least for the purposes of method can here be reduced to-the subject-object dichotomy: the mind is conceived as subject standing over against the physical object of the body. In Cartesian epistemology, the subject is related to its body in a way not essentially different from the relations it bears to all other objects of its cognition. Thus I here incorporate the mind-body dichotomy under that of the subject-object. (However, it should not be denied that the analyses of Dasein of fundamental ontology seem to miss the importance of reference to this standard Cartesian distinction.)

The primary claim of this paper is that Heidegger's fundamental ontology undermines this organisation of metaphysical conceptuality. The theory-praxis opposition is equally as essential to this conceptuality as that of the subject-object. Again, in Kant's philosophy it finds particularly clear expression; in the division of labour of the first two Critiques most noticeably. Again, Being and Time's existential analysis breaks up the conceptual rigidity of this dichotomy.

There is again little need for extensive Kant exegesis in this connection. I want simply to trace out the immanent logic of the destructuring of this distinction by fundamental ontology through its re-conceptualisation of time. It should be possible at this stage to move a little more quickly since it is simply a case of repeating our procedure. Once again a clear starting point is offered by a discussion in the Kant-book, a rare occasion in which Heidegger happily enters an ethical vocabulary.

Here, again, Heidegger clearly shows that there is not simply discontinuity between Kant's ethical theory and the existential analysis. The ethics of authenticity propounded in Being and Time can be understood to reconstrue a conceptual structure basic to practical reason, a conceptual opposition-perhaps the conceptual opposition-which remains fast beyond the interrogations of the presumptions of the tradition. In Kant's vocabulary, this opposition is located between inclination and duty, between sensuousness and reason. Inclinations, he points out, always have only a conditional value, which is constituted in reference to their end or goal. The value of this end always remains open to question. Moral value, on the other hand, cannot be 
conceived to be conditional in this way, and must therefore concern a domain of possible motivation beyond the immediacy of sensation-namely, within reason itself.

Reason, of course, is the structure of subjectivity for Kant. Thus to be determined purely by reason is to act solely in reference to oneself as rational being. This is the meaning of self-determination, and thus freedom. "Moral" qualifies precisely those actions which the self determines solely in reference to itself. If one stops here, rather than following Kant through his subsequent steps of universalisation, then one has described, if in unfamiliar language, the dilemma of the self of the existential analysis and the meaning of authenticity. Rather than between inclination and duty, sensuousness and reason, with Heidegger the distinction emerges between the placidity of the self of das Man, and the angstful being-towards-death of resoluteness.

On the other hand, the significance assigned to this moment differs essentially from Kant to Heidegger. Authenticity is not presented in Being and Time as an ethical norm, but rather in terms of the establishment of the possibility of ontology as such. As the disclosure of the truth of being, authenticity is the mode of being which arbitrates the "epistemological" enterprise of the analysis of existential understanding. But that is not to suggest that there is not, within the very structures of concern that make the disclosure of beings possible, the normativity of a demand for an authentic existence.

The logic of Heidegger's procedure in relation to the tradition is again apparent: the retainment of the kernel of truth, the tacit recognition that never came to language, and its displacement beyond the tension of the conceptual dualisms which distort it. The scientific comportment of Dasein shares the same existential structure as all of its understanding in general. This cannot be to collapse the theoretical into the practical, as might be initially thought and might often be suggested by commentators, for the two poles of this relation are defined only in terms of their opposition; rather, it is the dissolution of the dichotomy. The existential horizon upon which Heidegger thematises Dasein thus lies beyond the categories of theoretical and practical as they have functioned in the traditional discourse.

But in the last analysis, the success of Heidegger's project, conceived in this way, is dependent upon his re-casting of perhaps-to make a bold statement-the arch-metaphysical category of the will. The will performs a vital function in Kant's conceptual economy insofar as it designates the practical employment of reason. It is as such a faculty distinct from the theoretical faculties of understanding, imagination, etc., and has the task of executing, within a practical horizon of possibilities, whatever the theoretical faculties deem. In this sense, there is a clear legislative priority of the theoretical over the practical in Kant. The will is the practising of reason, and in this sense Kant determines it in relation to the concept of law-the practical execution of the laws of reason. "The will is thought of as a faculty of determining itself to action in accordance with the representation of certain 


\section{R. DUITS 105}

laws, and such a faculty can be found only in rational beings." 12 And again: "Only a rational being has the power to act according to his conception of laws, i.e., according to principles, and thereby has he a will."13

It is his faculty psychology which allows Kant to keep willing and understanding functionally separate, despite perhaps an oscillation between whether the will itself is the faculty of practical reason ("in accordance with the representation of certain laws"), or whether it is merely the executive of practical reason's commands. In any event, practical and theoretical reason function within distinct normativities, for Kant, one structured by the norm of truth, whose basic expression takes the form of judgement, and the other by the norm of goodness, whose basic expression takes the form of the imperative. Heidegger's collapsing of this distinction congeals the normativities of these two economies, and hence emerges what might be called, at least for expositional affect, an ethic of truths-"Now, in resoluteness the most primordial truth of Dasein has been reached, because it is authentic."14 -: Entschlossenheit, disclosure of the truth of being, is existentially imperative.

The procedure of the destruction of the category of the will can in fact be understood, if the neologism can be forgiven, in terms of a process of structuralisation: the structuralisation of the will. This can be made clearer with the aid of a brief illustration.

Einstein's relativity theories are held to have replaced basic tenets of Newtonian physics. In text books on the subject, the theory of gravity which general relativity propounds is frequently illustrated with an embedding diagram: a two-dimensional matrix, representing (four-dimensional) space-time, with a globe at its centre, representing a body. The body is supposed to distort the spatial-temporal matrix creating gradients and, consequently, vectors of movement, - we might say, not just incidently noting the etymology of Kant's terminological Neigung, inclin-ations. If one overlooks the initial illustrative paradox whereby gravity apparently makes gravity possible, then the figure makes apparent that gravity is no longer being understood in terms of a classical notion of force - a somewhat mysterious power hidden behind and effecting movement-but, rather, wholly in terms of structure, that is, in terms of a system of relations. What determines, for example, the trajectories of the heavenly bodies is just their complex of relations to one another within the matrix, or possibility of relation, that is designated Space-Time. SpatioTemporal relationships determine their movement; gravity is not forceful, it is purely structural.

In the same way, the step from the traditional discourse of the will-in all its various, especially post-Kantian, variations-to the existential analysis

12 Immanuel Kant, Groundwork for the Metaphysics of Morals, trans. by James Ellington (Indiana: Hackett, 1993), 427.

${ }_{13}^{13}$ Ibid., 412.

${ }^{14}$ Martin Heidegger, Sein und Zeit (Tübingen: Max Niemeyer, 2001, translated as Being and Time by Joan Stambaugh [SUNY, 1996]), 297. Nunmehr ist mit der Entschlossenheit die ursprünglichste weil eigentliche Wahrheit des Daseins gewonnen. 


\section{6}

\section{THE EXISTENTIAL TURN}

can be understood. This is perhaps the most basic import of what we are terming, recalling Kant's own achievement, the existential turn.

(That the will is generally understood by the tradition in terms of a concept of force is illustrated, admittedly more clearly than in Kant, by Schopenhauer's ontology. But nevertheless with Kant's "faculty of determining itself" something like force is surely implicated. The will is the motor that allows the steering of judgement to be first put into effect.)

In Heidegger's ontology there is no will. Instead, one finds a dissimulated subject in the form of a system of relationships finally structured by time. What determines the movements or actions of Dasein is the system of inclinations in which it stands, structured by the disclosure of meanings within its existential horizon. In this sense, one could speak of an existential topology: the temporal determination of Dasein structured by proclivous relationships of meaning. Structure has replaced force. Was this not the primary import of the movement known as structuralism? Here this figure of thought receives special significance since it concerns a category which supports, perhaps entirely, the system of the philosophy of the subject. It shows the necessity that metaphysics has a faculty theory of the subject. Explanation is attempted in terms of content rather than relation. The result is the creation of an inadmissible, unphenomenological, practical and ontological distance between the subject and its world.

\section{III}

I stated at the outset that my purpose in revisiting this central area of Heidegger interpretation is twofold: on the one hand, I want to emphasise the being-historical role of Being and Time, which emerges once the book is read in the light of the attempt to overcome metaphysics; and, on the other hand, I want to expose once again the significance of the reorganisation of philosophical concepts that the book accomplishes. In support of the second intention, let me conclude by briefly rehearsing some of the major consequences that Being and Time has had for recent intellectual history.

The primary import of the existential overcoming of metaphysics, it seems to me, is twofold. On the one hand, in the absence of a constitutive epistemological distance, the hierarchy of subject and object is lost, and as a result, truth becomes relativised absolutely to existentiality. What follows is either an ethic of truths or the rejection of veridical discourse altogether. The end of philosophy is announced. On the other hand, existential concepts are taken to be constitutive of identity, as a founding reference point of being. Whether implicitly or explicitly, the discourse of the human sciences is generally re-arranged around concepts of power, desire, jouissance, etc.

A final consequence, subtending these, emerges once it is remembered that the overcoming of metaphysics is accomplished as the raising of the question of being. This is the moment of the dissolution of intrinsic identityand with it of positivism, mechanism, elementism-and its relativisation to structure, system and relationship. It is no exaggeration to say that this theme 


\section{R. DUITS 107}

organises the entire contemporary discourse of the human sciences, yet few acknowledge or are aware that it was Heidegger's radical questioning which first shook the solid ground of being and revealed for thought the insecure terrain beyond metaphysics.

Department of Theology and Philosophy, St. Paul's School-London, United Kingdom

\section{References}

Heidegger, Martin, Being and Time, trans. by Joan Stambaugh (SUNY, 1996). , Kant and the Problem of Metaphysics, trans. by Richard Taft (Indiana University Press, 1997). , Kant und das Problem der Metaphysike (Frankfurt: Vittorio Klostermann, 1998).

Metaphysike und Nibilismus (Frankfurt: Gesamtausgabe Bd. 67, Vittorio Klostermann, 1999). Sein und Zeit (Tübingen: Max Niemeyer, 2001).

Kant, Immanuel, Critique of Pure Reason, trans. by Norman Kemp Smith (London: Macmillan, 1933).

Groundwork for the Metaphysics of Morals, trans. by James Ellington (Indiana: Hackett, 1993).

Kemp Smith, N., A Commentary to Kant's "Critique of Pure Reason" (London: Macmillan, 1923). 